\title{
Antitumor Effects of Interleukin-7 and Adoptive Immunotherapy on Human Colon Carcinoma Xenografts
}

\author{
William J. Murphy, * Timothy C. Back, ${ }^{3}$ Kevin C. Conlon, ${ }^{*}$ Kristin L. Komschlies, ${ }^{*}$ John R. Ortaldo, ${ }^{*}$ \\ Thomas J. Sayers, ${ }^{5}$ Robert H. Wiltrout, ${ }^{\star}$ and Dan L. Longo* \\ * Laboratory of Leukocyte Biology and ${ }^{\ddagger}$ Laboratory of Experimental Immunology, Biological Response Modifiers Program, National \\ Cancer Institute-Frederick Cancer Research and Development Center; and ${ }^{\S}$ Biological Carcinogenesis and Development Program, \\ Program Resources, Inc./DynCorp, National Cancer Institute-Frederick Cancer Research and Development Center, \\ Frederick, Maryland 21702
}

\begin{abstract}
The antitumor properties of recombinant human IL-7 (rhIL-7) on a human tumor was evaluated by engrafting a human colon carcinoma into immunodeficient mice and then treating the mice with rhIL-7 and adoptively transferred human peripheral blood $T$ cells. It was found that rhIL-7 alone had no effect on the survival of the tumor-bearing recipients. However, the combination of rhIL-7 and human T cells significantly promoted the survival of the recipients compared with mice receiving either treatment by itself. When the surviving mice were analyzed 6 mo later for the degree of human cell engraftment, the recipients receiving both rhIL-7 and human $\mathrm{T}$ cells had greater numbers of human $\mathrm{CD8}^{+} \mathrm{T}$ cells in the spleens. However, the human $T$ cells recovered from the surviving mice showed low lytic activity against the tumor in vitro. Supernatants from human $T$ cells cultured with the tumor and rhIL-7 in vitro were found to inhibit tumor growth and were demonstrated to contain high levels of IFN- $\gamma$. Antibodies to IFN- $\gamma$ neutralized the growth inhibition of the tumor both in vitro and in vivo demonstrating that the in vivo mechanism underlying the antitumor effects of this regimen was partly dependent on the production of IFN- $\gamma$ by the $T$ cells and not their cytolytic capability. Interestingly, systemic administration of rhIFN- $\gamma$ to tumor-bearing mice yielded little antitumor effect suggesting that adoptive immunotherapy with rhIL-7 was superior possibly because of the continuous local release of the cytokines. Therefore, rhIL-7 may be of clinical use as an antineoplastic agent and the human/mouse model is a potentially important preclinical model for in vivo evaluation of the efficacy of this and other immunotherapies. (J. Clin. Invest. 1993. 92:1918-1924.) Key words: SCID/human mouse • cytokines • cancer treatment • T cells • interleukin-7
\end{abstract}

\section{Introduction}

IL-7 is a cytokine that was originally described as a factor produced by bone marrow stromal cells that exerted proliferative effects on B cell precursors in vitro $(1,2)$. IL-7 also has been demonstrated to affect murine thymocyte proliferation in vitro (3) and to provide a costimulatory signal for resting T cells (4).

Address correspondence to William J. Murphy, Ph.D., Laboratory of Leukocyte Biology, Biological Response Modifiers Program, NCIFCRDC, Building 567, Room 141, Frederick, MD 21702. 1993.

Received for publication 8 March 1993 and in revised form 20 May

The Journal of Clinical Investigation, Inc.

Volume 92, October 1993, 1918-1924
IL-7 has been shown to induce the proliferation of human T cells in vitro (5) and has been shown to augment lymphokine activated killer activity (6), leading to the hypothesis that IL-7 may be of clinical use as an antineoplastic agent. In murine studies, it has been demonstrated that when IL-7 was transfected into tumor cells, the subsequent transfer of these cells into syngeneic recipients resulted in the increased rejection of the cells by T-cell-dependent responses of the host $(7,8)$. Additionally, other studies performed in the mouse demonstrated that IL-7 induced cytotoxic $T$ cells that could be adoptively transferred in vivo and protect mice against syngeneic tumors $(9,10)$. However, the antitumor effects of recombinant human IL-7 (rhIL-7) ${ }^{1}$ against a human tumor have not been examined.

The ability to engraft human cells, both normal and neoplastic, into immunodeficient mice has allowed for the examination of various potential biological therapies on human tumors in an in vivo setting (11-13). In our studies, we chose to evaluate the efficacy of rhIL-7 against a human colon carcinoma in vivo. We report here that the administration of rhIL-7 with adoptive immunotherapy (AIT) significantly prolonged the survival of human tumor-bearing mice. Furthermore, it was determined that the increase in survival was correlated with the production of IFN- $\gamma$ by the human $\mathrm{T}$ cells in response to the tumor and rhIL-7. Thus, adoptive immunotherapy with rhIL-7 is worthy of clinical evaluation in cancer patients. In addition, these studies suggest that the human/mouse model may be useful in evaluating the in vivo efficacy of biological approaches to the treatment of human tumors.

\section{Methods}

Mice. C.B-17 scid/scid (SCID) mice were bred in our own colony at the NCI-FCRDC (Frederick, MD). Mice were used at 8-12 wk of age and were kept under specific pathogen-free conditions. SCID mice were housed in microisolator cages and all food, water, and bedding were autoclaved before use. SCID mice received trimethoprim/sulfamethoxazole ( $40 \mathrm{mg}$ trimethoprim and $200 \mathrm{mg}$ sulfamethoxazole / 320 $\mathrm{ml}$ ) in suspension in their drinking water.

Cytokines. rhIL-7 at $2-5 \times 10^{7} \mathrm{U} / \mathrm{mg}$ was kindly provided by $\mathrm{Dr}$. Connie Faltynek (Sterling Winthrop Pharmaceuticals Research Division, Malvern, PA) rhIFN- $\gamma$ at $2.5 \times 10^{7} \mathrm{U} / \mathrm{mg}$ was generously donated by Genentech Inc. (South San Francisco, CA).

Tumor cell line. The tumor cell line used for these studies was the HT29 human colon adenocarcinoma, which we have previously demonstrated grows in immunodeficient SCID mice (13). The HT29 cells were maintained either by serial interperitoneal passage in athymic

1. Abbreviations used in this paper: AIT, adoptive immunotherapy; huPBL, human PBL; LU, lytic units; NU, neutralizing units; rh, recombinant human; SCID, C.B-17 scid/scid (mice). 
mice or by growth in cell culture in DME supplemented with $10 \%$ FBS, L-glutamine ( $2 \mathrm{mM})$, sodium pyruvate $(1 \mathrm{mM})$, nonessential amino acid solution ( $1 \%$ ), and $50 \mathrm{IU} / \mathrm{ml}$ penicillin $+50 \mu \mathrm{g}$ streptomycin. For injection into mice, the cells were harvested and counted, and $1 \times 10^{6}$ viable cells were injected intraperitoneally. Tumor-bearing mice were then monitored for tumor development and progression. Moribund mice were euthanized. In the experiments where human $T$ cells were also transferred, mice received an intraperitoneal injection of HT29 followed $2 \mathrm{~h}$ later with an intraperitoneal injection of $5 \times 10^{7}$ purified human $\mathrm{T}$ cells.

In vivo experiments. All mice received $20 \mu \mathrm{l}$ of anti-asialo GM1 ( $\alpha$ ASGM1) (Wako Chemicals, Dallas, TX) intravenously to remove host natural killer cells (14) the day before injection of human $T$ cells and tumor. Peripheral blood mononuclear cells were obtained via leukapheresis from healthy donors on a cell separator (model 2997; Cobe, Lakewood, $\mathrm{CO}$ ). All donors signed an informed consent statement. Purified mononuclear cells were obtained after Ficoll Hypaque (Pharmacia Fine Chemicals, Uppsala, Sweden) density centrifugation and washed twice in PBS. For most of the experiments, the cells were then placed over a nylon wool (Sigma Immunochemicals, St. Louis, MO) column for $1 \mathrm{~h}$ at $37^{\circ} \mathrm{C}$ to remove $\mathrm{B}$ cells. The eluted cells were then collected and counted on a Coulter counter (Coulter Corp., Hialeah, FL). $5 \times 10^{7}$ human T cells were resuspended in $0.5 \mathrm{ml} \mathrm{HBSS}$ and were injected intraperitoneally into recipient mice. All experiments had 6-15 mice per group, and each experiment used lymphocytes from one donor. Some groups also received 5-10 $\mu$ g i.p. of rhIL-7 (Sterling Winthrop Pharmaceuticals Research Division ) daily for $2 \mathrm{wk}$ after cell transfer. Some groups also received $2 \times 10^{5} \mathrm{U}$ i.p. of rhIFN- $\gamma$ given daily i.p. for $10 \mathrm{~d}$. In the studies examining the effect of rhlL-7 on human cell engraftment in SCID mice, $1 \times 10^{8}$ unfractionated human PBL (huPBL) or $5 \times 10^{7}$ purified human T cells were injected intraperitoneally into SCID recipients with the mice being assayed 6-8 wk after huPBL transfer.

Flow cytometric analysis of cells. The following anti-human mAb were used: CD4 (Leu3a), CD8 (Leu2a), CD3 (Leu4), CD19 (a B-cell marker), CD25, and HLA-DR were directly FITC-labeled or biotinconjugated (Becton-Dickinson Immunocytometry Systems, Mountain View, CA ). Each two-color fluorescence study included a double-negative control of mouse IgG-FITC/mouse IgG-PE (Becton-Dickinson Immunocytometry Systems). HLA-ABC-FITC was purchased from Olympus (Lake Success, NY). After preparation of single-cell suspensions from the various tissues, the cells were counted and the samples were blocked with $2 \%$ human AB serum (Gibco BRL, Grand Island, NY) before primary antibody incubation to saturate human Fc receptors. Cells were then fixed in $1 \%$ paraformaldehyde and analyzed on a flow cytometer (Epics; Coulter Corp.). All experiments were performed at least three times with representative experiments or mice being shown.

Cytotoxicity assays. At the specified time points, appropriate target cells were labeled by incubation for $1 \mathrm{~h}$ at $37^{\circ} \mathrm{C}$ with $\mathrm{Na}^{51} \mathrm{CrO}_{4}(\mathrm{New}$ England Nuclear, Boston, MA) (specific activity approximately 400 $\mu \mathrm{Ci} / \mu \mathrm{g})$. After this incubation, the target cells were washed three times in RPMI supplemented with $2 \%$ FCS before use in the assay. Effector cells (consisting of both human and mouse cells) obtained from the spleens of the surviving mice and were added to each well of a 96-well plate (model 3797; Costar, Cambridge, MA) to achieve effector/target $(\mathrm{E} / \mathrm{T})$ cell ratios of $50 / 1,25 / 1,12.5 / 1$, and $6.25 / 1$. Four replicate wells were used in these assays. After a standard 4-h incubation, the supernatants were harvested and analyzed on a gamma counter ( model 5500; Beckman Instruments, Irvine, CA). The curve generated by these data was used to calculate lytic potential of these effector cells. The results were expressed as natural killer lytic unit (LU) values at $50 \%$ lysis based on several E/T ratios, and a Student's $t$ test was performed to determine statistical differences.

Antibody neutralization. The murine mAb E43 (anti-TNF- $\alpha$ ) at 5,000 neutralizing units (NU)/ml and A7 (anti-IFN- $\gamma$ ) at 4,900 NU/ $\mathrm{ml}$ were obtained from the Biological Response Modifiers Program repository (Frederick, MD). Neutralizing antibodies at $1,000 \mathrm{NU} / \mathrm{ml}$ were incubated with PBL supernatants diluted $1: 5$ in media $2 \mathrm{~h}$ at room temperature before their addition to HT29 cells. For in vivo neutralization studies, tumor-bearing mice received $490 \mathrm{NU}$ of anti-IFN- $\gamma$ in 0.2 $\mathrm{ml}$ i.p. for $7 \mathrm{~d}$. Normal mouse serum obtained from normal C57BL/ 6 mice was used $(0.2 \mathrm{ml}$ i.p.) as a source for irrelevant control antibodies. IFN- $\gamma$ levels were determined through the use of a virus neutralization assay (Clinical Immunology Services, NCI-FCRDC, Frederick, MD), and a Student's $t$ test was performed to determine statistical differences.

Growth inhibition assays. Cell growth of HT29 cells was measured in the presence or absence of experimental agents using a crystal violet staining assay. Rapidly growing HT29 cells were harvested, counted, and added to 96 -well microtiter plates at 1,250 cells/well in a volume of $100 \mu \mathrm{l}$. After $24 \mathrm{~h}$, dilution of PBL supernatants (in the presence or absence of neutralizing antibodies) were added to the HT29 cells in triplicate in a volume of $100 \mu \mathrm{l}$. After $4 \mathrm{~d}$ of incubation at $37^{\circ} \mathrm{C}$, media was removed and cells were fixed for $5 \mathrm{~min}$ in methanol, dried, and then stained in $0.1 \%$ crystal violet for $15 \mathrm{~min}$. The excess stain was removed by washing the plates in distilled water and the plates were dried. The dye was solubilized by the addition of $200 \mu \mathrm{l}$ of $1 \%$ SDS, and plates were incubated for $2 \mathrm{~h}$ at $37^{\circ} \mathrm{C}$ to allow sufficient time for complete dye solubilization. Plates were agitated gently, and the spectrophotometric absorbance at $570 \mathrm{~nm}$ (A570) was read on a microplate reader (model MR 500; Dynatech Labs Inc., Chantilly, VA) with a reference setting of $410 \mathrm{~nm}$. The percentage growth inhibition was calculated from the formula:

percent growth inhibition $=1-\frac{\mathrm{A} 570 \text { of treated cells }}{\mathrm{A} 570 \text { of untreated cells }} \times 100$

Statistical analysis. Significant differences in survival times were detected by generalized Wilcoxon or Mantel statistics using the BMDPIL program.

\section{Results}

Effect of rhIL-7 and AIT on survival in tumor-bearing recipients. Since IL-7 has been shown to provide antitumor effects in mice (10), we wanted to evaluate its efficacy against a human tumor in vivo. Additionally, since IL-7 was demonstrated to augment $T$ cell responses (3-8), we examined the effects of rhIL-7 and adoptively transferred human $\mathrm{T}$ cells in tumorbearing mice. Immunodeficient SCID mice were injected intraperitoneally with $1 \times 10^{6}$ HT29 colon carcinoma cells, which we have previously determined leads to metastatic spread of tumor and kills the mice after 40-60 d (13). By administration of anti-ASGM1 to remove SCID natural killer function, the majority of antitumor effects should be directly caused by the therapy being evaluated (14). After injection of tumor, the mice were then injected intraperitoneally with $5 \times 10^{7}$ human $T$ cells several hours later. Purified human $T$ cells were used, since the B cells in huPBL obtained from EBV-seropositive donors can transform in SCID mice and give rise to $B$ cell lymphomas that can complicate the interpretation of the experiment $(11,14)$. Some groups also received subsequent daily injections of rhIL-7 (10 $\mu \mathrm{g}$ in $0.2 \mathrm{ml}$ PBS) or PBS alone intraperitoneally for $10 \mathrm{~d}$. The mice were then monitored for effects on survival with necropsy being performed on moribund mice to confirm that the tumor was the cause of death. The results demonstrate that rhIL-7, when given in conjunction with human $\mathrm{T}$ cells, resulted in significantly $(P<0.001)$ prolonged survival when compared to administration of human $T$ cells alone in mice treated the same day they received tumor (Fig. 1 and Table I, experiment $A$ ). The administration of rhIL-7 alone did not provide any protective effect in the survival time of tumor-bearing recipients (Fig. 1 and Table I, experiment $C$ ). 


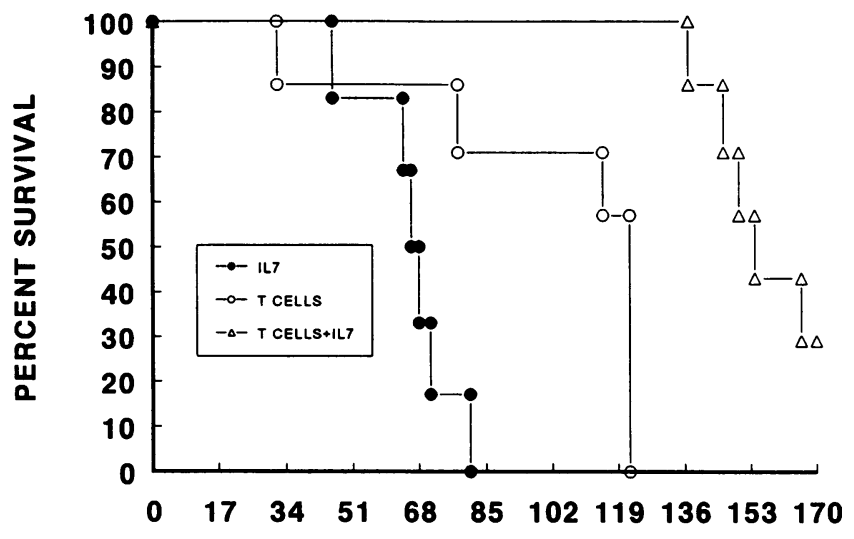

DAYS AFTER TUMOR INJECTION

Figure 1. Effects of rhIL-7 and AIT on survival of tumor-bearing SCID mice. Mice were injected intraperitoneally with HT29 as described in the Methods. Several hours later, mice were injected with human T cells with or without rhIL-7 $(10 \mu \mathrm{g} / \mathrm{d}$ for $10 \mathrm{~d})$. Survival was then monitored, and moribund mice were euthanized. Control mice treated with HBSS alone had similar survival to those treated with rhIL-7 alone (data not shown).

However, transfer of human $\mathrm{T}$ cells alone did prolong the survival of the tumor-bearing mice. The extent of the protection in the recipients receiving human $T$ cells alone tended to vary with the huPBL donor. In some experiments, the recipients receiving human $T$ cells alone did clear the tumor in a small percentage of mice, although the coadministration of $T$ cells plus rhIL-7 was consistently superior in its protection, regardless of the donor when treatment was started the same day as

Table I. Effect of rhIL-7 and AIT on Survival in Tumor-bearing Mice

\begin{tabular}{cclc}
\hline $\begin{array}{c}\text { Experiment } \\
\text { number }\end{array}$ & $\begin{array}{c}\text { Initiation } \\
\text { of therapy* }\end{array}$ & \multicolumn{1}{c}{ Treatment $^{*}$} & $\begin{array}{c}\text { Mean } \\
\text { DOD }^{\beta}\end{array}$ \\
\hline 1 & $2 \mathrm{~h}$ & HBSS & 47 \\
& & T cells & $109^{\prime \prime}$ \\
& & rhIL-7 and T cells & $135^{\top}$ \\
2 & $7 \mathrm{~d}$ & HBSS & 45 \\
& & T cells & 53 \\
& & rhIL-7 and T cells & $67^{* *}$ \\
3 & \multirow{2}{*}{$14 \mathrm{~d}$} & HBSS & 39 \\
& & rhIL-7 & 39 \\
& & T cells & 51 \\
& & rhIL-7 and T cells & $75^{* *}$
\end{tabular}

\footnotetext{
* Time of therapy initiation after injection of HT29 tumor. ${ }^{\ddagger}$ Mice were treated as described in Methods. Each experiment used a different donor. Each experiment had 6-15 mice per group. ${ }^{8}$ Mean day of death (DOD) after-HT29 tumor challenge. Average of 6-15 mice per group with significance determined by using Mantel-Cox statistics. "One out of six mice survived tumor, mice receiving human T cells survived significantly $(P<0.001)$ greater than mice receiving tumor alone. 'Four out of six mice survived tumor, and mice receiving human $\mathrm{T}$ cells and rhIL-7 survived significantly $(P<0.001)$ longer than mice receiving human $\mathrm{T}$ cells alone. ${ }^{* *}$ Mice receiving human T cells and rhIL-7 survived significantly $(P<0.01)$ longer than mice receiving rhIL-7 or HBSS alone.
}

tumor challenge. To determine if the combination of rhIL-7 and AIT was efficacious against a larger and more disseminated tumor burden, mice were given tumor 1 and $2 \mathrm{wk}$ before the start of immunotherapy. The results demonstrate that rhIL-7 and AIT administration resulted in significantly $(P$ $<0.01$ ) greater survival in tumor-bearing recipients compared with mice not receiving treatment (Table I). However, with this tumor burden there were no mice surviving $>85 \mathrm{~d}$, regardless of the treatment regimen used and the differences between the groups receiving human $T$ cells alone and groups receiving human T cells and rhIL-7 were not statistically different. Thus, the administration of rhIL-7 with AIT results in significant antitumor effects against a human colon carcinoma in SCID mice at a variety of tumor burdens. However, tumor cure and the most significant antitumor effects of rhIL-7 occur only with tumor burdens around $10^{6}$ cells.

Effect of rhIL-7 on long-term engraftment of transferred human lymphocytes. It was then of interest to determine the effect of rhIL-7 on the engraftment of the transferred huPBL in the tumor-bearing mice. We have previously demonstrated that activation of huPBL with anti-CD3 results in greater long-term engraftment in SCID mice (13). Therefore, one mechanism by which rhIL-7 and AIT may protect tumor-bearing mice is by the improvement of human $T$ cell engraftment in the mice. Mice surviving the tumor in experiments where tumor cells and therapy were started on the same day were killed $6 \mathrm{mo}$ after the start of tumor therapy. In one experiment, unfractionated huPBL had been transferred (Fig. 2 and Table II, experiment A). It was demonstrated that rhIL-7 administration did indeed result in improved peripheral human $\mathrm{T}$ cell engraftment in the recipients. Although we have previously found that the predominant T cell (CD4 or CD8) to engraft tended to vary with the donor $(13,14)$, in most instances, $\mathrm{CD}^{+} \mathrm{T}$ cells predominantly engrafted in the mice (Fig. 2). Additionally, these $T$ cells also expressed HLA-DR, indicating that they were in an activated state for a prolonged period of time in the SCID recipients. Interestingly, there was also no evidence of tumor in these long-term surviving mice, suggesting that rhIL-7 and AIT had indeed cleared some mice of a tumor burden of $10^{6}$ cells. It was also demonstrated that administration of rhIL-7 could promote human lymphocyte engraftment in non-tumor-bearing SCID recipients (Table III). Thus, rhIL-7 administration can improve long-term $T$ cell engraftment in tumor-bearing SCID mice, which may contribute to the improved survival of tumor-bearing mice receiving this regimen. However, some mice receiving human $\mathrm{T}$ cells alone or human $\mathrm{T}$ cells with rhIL-7 were capable of clearing the tumor yet displayed little longterm T cell engraftment (Fig. 2 and Table II). Thus, other mechanisms may be responsible for the antitumor effects of rhIL-7 with AIT.

Cytotoxic capability of human $T$ cells cocultured with tumor in vitro. We then wanted to determine the mechanism by which rhIL-7 and AIT protected the tumor-bearing mice. We had previously assessed the capacity of the recovered human cells from the surviving mice to lyse the tumor and demonstrated that the recovered human cells had no significant lytic activity towards the tumor in vitro (data not shown) (13). Since it may be that the human $T$ cells were initially cytolytic for the tumor, but after prolonged exposure in the murine host they lost their cytolytic ability, we then determined the effects of rhIL-7 on the generation of tumor-specific cytotoxic T lymphocytes after coculture in vitro. huPBL were cocultured with 
1 Tumor + huPBL
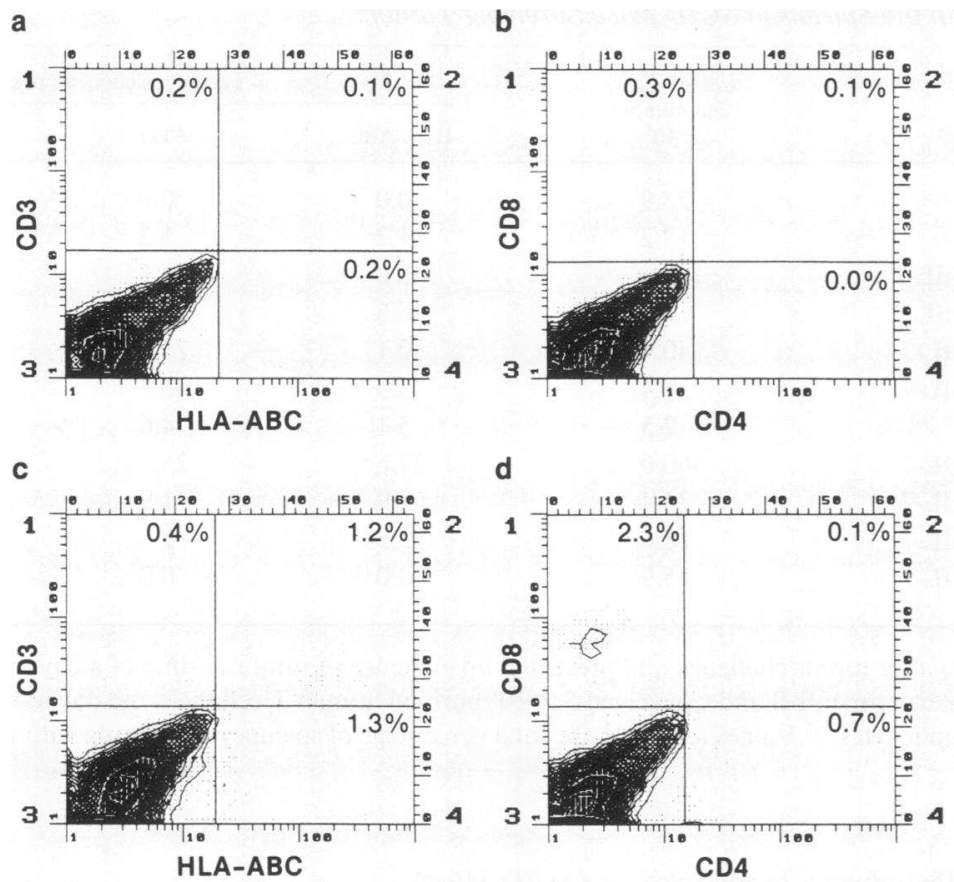

2 Tumor + huPBL

3 Tumor + huPBL + IL-7
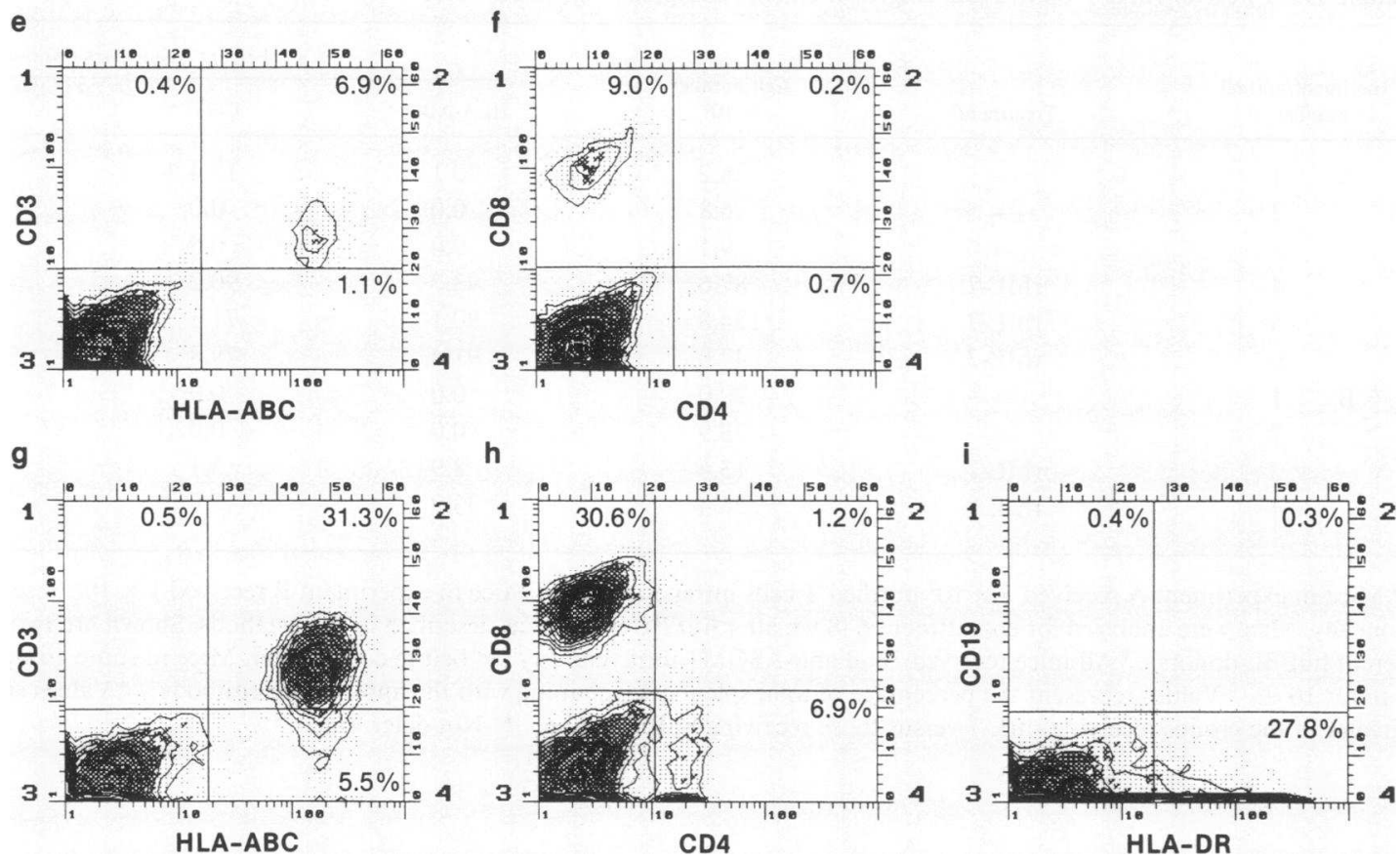

Figure 2. Effects of rhIL-7 on long-term human T cell engraftment in tumor-bearing SCID mice. SCID recipients surviving the tumor for $>6$ mo were killed and human $T$ cell content was determined in the spleens of the mice by flow cytometric analysis. Representative of three experiments with two to three mice per group.

tumor, with or without rhIL-7, for $4 \mathrm{~d}$, and were then assayed for cytotoxic capability against the tumor. The results demonstrate that the human T cells only displayed significantly $(P$ $<0.05$ ) increased but modest levels of cytotoxicity towards the HT29 tumor when $1,000 \mathrm{U} / \mathrm{ml}$ of rhIL-7 was included. However, when the huPBL were cultured with the tumor and rhIL-7 $(>100 \mathrm{U})$ significant $(P<0.05)$ increases in cytolytic activity were observed (Table IV). Thus, the contribution of the cytotoxicity to the antitumor affects is not clear.
Induction of cytokine production after coculture of huPBL with tumor and rhIL-7. We then assayed supernatants from the huPBL that were cocultured with tumor and rhIL-7 in vitro for any potential inhibitory effects on the HT29 tumor. We have previously demonstrated that the HT29 colon carcinoma is sensitive to rhIFN- $\gamma$ and TNF- $\alpha$ in vitro (13). When supernatants from human cells cocultured with rhIL-7 and tumor were placed with HT29 in vitro, the supernatants significantly inhibited the growth of the tumor (Table V). Antibodies to rhIFN- $\gamma$ 
Table II. Human T Cell Engraftment in the Spleens of SCID Mice Surviving Tumor*

\begin{tabular}{|c|c|c|c|c|c|c|c|}
\hline \multirow{2}{*}{\multicolumn{2}{|c|}{$\begin{array}{c}\text { Experiment/animal } \\
\text { number }\end{array}$}} & \multirow[b]{2}{*}{ Treatment $^{\ddagger}$} & \multirow{2}{*}{$\begin{array}{c}\text { Cell number } \\
\times 10^{6}\end{array}$} & \multicolumn{4}{|c|}{ Percent splenocytes positive for: 8} \\
\hline & & & & HLA-ABC & CD3 & CD4 & CD8 \\
\hline \multirow[t]{4}{*}{ A } & 1 & huPBL & 23.9 & 0.0 & 0.0 & 0.0 & 0.0 \\
\hline & 2 & huPBL & 12.2 & 1.2 & 1.2 & 0.7 & 2.3 \\
\hline & 3 & huPBL + rhIL-7 & 103.9 & 8.0 & 6.9 & 0.7 & 9.0 \\
\hline & 4 & huPBL + rhIL-7 & 7.5 & 36.8 & 31.3 & 6.9 & 30.6 \\
\hline \multirow[t]{2}{*}{ B } & 1 & $\mathrm{~T}$ cells + rhIL -7 & 40.4 & 30.1 & 25.2 & 5.1 & 20.7 \\
\hline & 2 & $\mathrm{~T}$ cells + rhIL-7 & 38.4 & 43.3 & 40.5 & 10.9 & 31.9 \\
\hline \multirow[t]{5}{*}{$\mathrm{C}$} & 1 & $\mathrm{~T}$ cells & 2.5 & 5.1 & 4.6 & 2.1 & 2.9 \\
\hline & 2 & $\mathrm{~T}$ cells + rhIL- 7 & 460.0 & 39.6 & 25.7 & 3.1 & 22.0 \\
\hline & 3 & T cells + rhIL-7 & 33.4 & 1.9 & 1.9 & 1.1 & 1.7 \\
\hline & 4 & $\mathrm{~T}$ cells + rhIL -7 & 18.6 & 2.3 & 2.1 & 0.8 & 1.5 \\
\hline & 5 & $\mathrm{~T}$ cells + rhIL- 7 & 15.9 & 0.0 & 0.0 & 0.0 & 0.0 \\
\hline
\end{tabular}

* All surviving mice were assayed 5-6 mo after tumor challenge and presented no evidence of tumor at time of assay. ${ }^{\ddagger}$ Mice in experiment $A$ received $1 \times 10^{8}$ huPBL, whereas mice in experiments $B$ and $C$ received $5 \times 10^{7}$ purified human $T$ cell the same day as tumor challenge. Each experiment used a different donor for lymphocytes. ${ }^{\$}$ Values represent the total percentage of splenocytes staining with the appropriate antibody.

Table III. Effect of rhIL-7 on huPBL Engraftment in the Spleens of SCID Mice*

\begin{tabular}{|c|c|c|c|c|c|c|c|}
\hline \multirow{2}{*}{\multicolumn{2}{|c|}{$\begin{array}{l}\text { Experiment/animal } \\
\text { number }\end{array}$}} & \multirow{3}{*}{$\frac{\text { Treatment }^{\ddagger}}{-}$} & \multirow{3}{*}{$\begin{array}{c}\begin{array}{c}\text { Cell number } \\
\times 10^{6}\end{array} \\
36.2\end{array}$} & \multicolumn{4}{|c|}{ Percent splenocytes positive for: 8} \\
\hline & & & & \multirow{2}{*}{$\begin{array}{c}\text { HLA-ABC" } \\
20.1\end{array}$} & \multirow{2}{*}{$\frac{\text { CD3" }}{13.4}$} & \multirow{2}{*}{$\begin{array}{c}\text { CD4" } \\
6.9\end{array}$} & \multirow{2}{*}{$\frac{\mathrm{CD} 8 "}{9.0}$} \\
\hline A & 1 & & & & & & \\
\hline & 2 & - & 6.8 & 0.0 & 0.0 & 0.0 & 0.0 \\
\hline & 3 & - & 9.1 & 0.0 & 0.0 & 0.0 & 0.0 \\
\hline & 4 & rhIL-7 & 87.6 & 93.7 & 90.2 & 23.9 & 62.0 \\
\hline & 5 & rhIL-7 & 124.8 & 80.1 & 71.3 & 21.1 & 51.4 \\
\hline & 6 & rhIL-7 & 47.0 & 91.4 & 79.8 & 26.5 & 50.4 \\
\hline \multirow[t]{4}{*}{ B } & 1 & - & 20.0 & 0.0 & 0.0 & $\mathrm{ND}^{* *}$ & ND \\
\hline & 2 & - & 38.9 & 0.0 & 0.0 & ND & ND \\
\hline & 3 & rhIL-7 & 13.6 & 8.9 & 3.1 & ND & ND \\
\hline & 4 & rhIL-7 & 226.4 & 33.9 & 7.9 & ND & ND \\
\hline
\end{tabular}

${ }^{*}$ Mice in experiment A received $5 \times 10^{7}$ purified T cells intraperitoneally. Mice in experiment B received $1 \times 10^{8}$ unseparated huPBLintraperitoneally. Mice were analyzed for engraftment 6-8 wk after huPBL transfer, as described in the Methods. Shown are two experiments using different huPBL donors. ${ }^{\ddagger}$ All mice received $20 \mu \mathrm{l}$ anti-ASGM 1 intravenously $1 \mathrm{~d}$ before cell transfer. Mice in some groups received $10 \mu \mathrm{g}$ rhIL-7 i.p. for $10 \mathrm{~d}$. ${ }^{8}$ Values represent the percentage of total splenocytes staining with the appropriate antibody. "Values significantly $(P<0.001)$ greater in the groups receiving rhIL-7 versus those receiving huPBL alone. ${ }^{* *}$ Not determined.

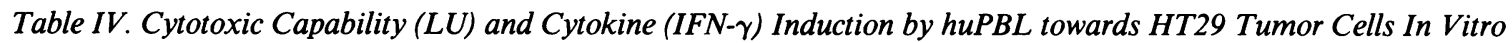

\begin{tabular}{|c|c|c|c|}
\hline \multirow[b]{2}{*}{ Effector population ${ }^{*}$} & \multicolumn{2}{|c|}{ Target cell $(\mathrm{LU}+\mathrm{SE})^{*}$} & \multirow{2}{*}{$\begin{array}{c}\text { IFN- } \gamma \text { levels } \\
(\mathrm{U}+\mathrm{SE})^{s}\end{array}$} \\
\hline & K562 & HT29 & \\
\hline huPBL + rhIL-7 (10 U) & $110.4(12.9)$ & $90.2(5.1)$ & $627(25)$ \\
\hline huPBL + rhIL-7 (100 U) & $131.8(10.7)$ & $110.3(6.0)$ & $1034(82)$ \\
\hline huPBL + rhIL-7 (1,000 U) & $411.0(56.1)$ & $136.3(9.6)$ & $1685(34)$ \\
\hline huPBL + HT29 & $171.5(6.9)$ & $84.3(7.9)$ & $3845(75)$ \\
\hline huPBL + HT29 + rhIL-7 (10 U) & $229.2(13.3)$ & $68.2(3.4)$ & $3937(75)$ \\
\hline huPBL + HT29 + rhIL-7 (100 U) & $84.3(11.4)$ & $142.5(3.4)$ & $7322(146)$ \\
\hline huPBL + HT29 + rhIL-7 $(1,000 \mathrm{U})$ & $149.1(9.7)$ & $228.7(5.1)$ & $12,141(242)$ \\
\hline
\end{tabular}

${ }^{*} \mathrm{LU}$ with SE in which there is $\geq 50 \%$ lysis per $1 \times 10^{7}$ cells. ${ }^{\ddagger}$ huPBL were suspended in tissue culture media under various conditions and assayed for cytotoxicity after $4 \mathrm{~d}$. ${ }^{3}$ Assay was performed and the amount of units of IFN- $\gamma$ were determined as described in Methods. 
Table V. Growth Inhibitory Effects of Supernatants from rhIL-7-treated huPBL on HT29 Colon Carcinoma Cells

\begin{tabular}{ccccc}
\hline & \multicolumn{3}{c}{ Percent growth inhibition ${ }^{*}$} \\
\cline { 2 - 5 } Supernatant dilution & & Media & Anti-IFN- $\gamma^{5}$ & Anti-TNF- $\alpha^{\prime \prime}$ \\
\hline huPBL + HT29 + IL-7 (100) & $1: 20$ & 67 & 33 & 51 \\
$1: 80$ & 53 & 0 & 53
\end{tabular}

* Supernatants from 7-d in vitro cultures were diluted (1:5) in media in the presence or absence of neutralizing antibodies. After $2 \mathrm{~h}$, incubation at room temperature, growth inhibitory activity against HT29 cells was measured in a 4-d assay. ${ }^{\ddagger}$ Growth inhibition calculated as described in Methods. Neutralizing antibody to IFN- $\gamma$ at $1,000 \mathrm{NU} / \mathrm{ml}$. " Neutralizing antibody to TNF- $\alpha$ at $1,000 \mathrm{NU} / \mathrm{ml}$.

could partially reverse the inhibitory effect when present at concentration necessary to neutralize all the IFN- $\gamma$, suggesting that IFN- $\gamma$ production by the human T cells could be the mechanism for tumor protection in vivo. Additionally, rhIFN- $\gamma$ alone was capable of inhibiting tumor growth (data not shown) (13). Neutralizing antibodies to TNF- $\alpha$ could only slightly reduce the inhibiting effects of the supernatants. To determine if rhIL-7 induces IFN- $\gamma$ production by huPBL in vitro, the levels of IFN- $\gamma$ were determined under the various culture conditions. It was found that rhIL-7 alone induced a dose-dependent production of IFN- $\gamma$ by huPBL after $4 \mathrm{~d}$ of culture (Table IV). Additionally, the coculture of the human $T$ cells with the tumor resulted in high levels of IFN- $\gamma$ production. Yet, the coincubation of huPBL, rhIL-7 ( $>100 \mathrm{U}$ ), and tumor resulted in significantly $(P<0.05)$ increased IFN- $\gamma$ production compared to huPBL and HT29 alone. These in vitro results also suggest that the mechanism underlying the protective effects of rhIL-7 and AIT in tumor-bearing mice may be partially attributed to the production of cytokines by the human $\mathrm{T}$ cells in response to rhIL-7. Thus, these cytokines had direct cytostatic or cytotoxic effects on the tumor in the absence of a cytotoxic $T$ cell response. Although IFN- $\gamma$ appears to be critical to the growth inhibiting effects of rhIL-7 + T cells on HT29, it has been established that there is a strong synergy between IFN- $\gamma$ and

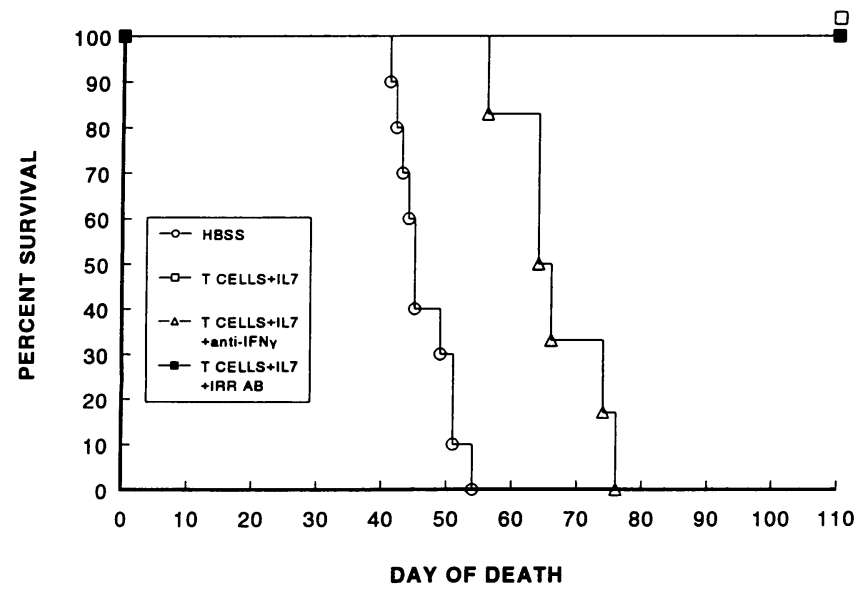

Figure 3. Effects of anti-IFN- $\gamma$ antibodies on tumor protection in vivo. Tumor-bearing SCID mice received human T cells with rhIL-7 and neutralizing antibodies to rhIFN- $\gamma$ or normal mouse serum from C57BL/6 mice as an irrelevant antibody (IRR $A B)$ control, as described under "Antibody neutralization" in Methods.

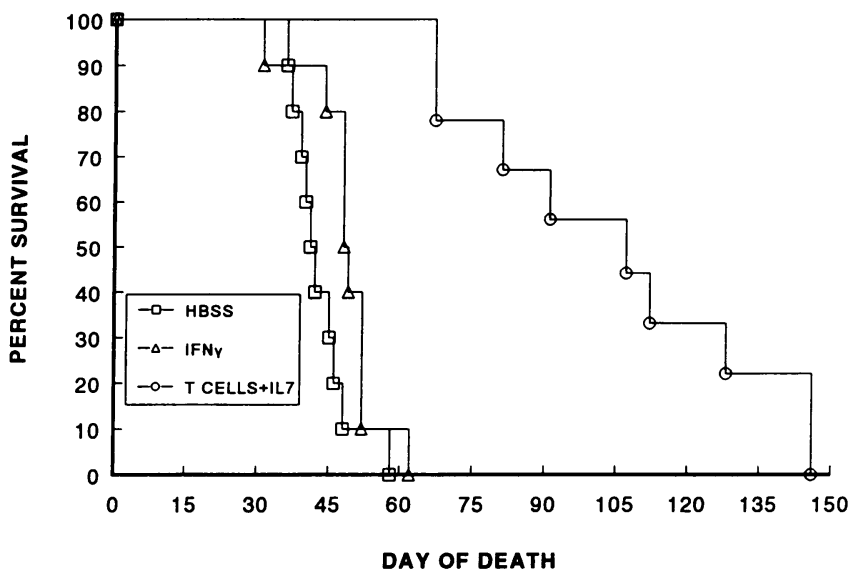

Figure 4. Comparison of rhIL-7 and AIT versus systemic administration of rhIFN- $\gamma$ in tumor-bearing mice. SCID mice received either rhIL-7 and AIT or rhIFN- $\gamma$, as described in Methods.

TNF- $\alpha$ on this cell line in vitro (13). Thus, it is possible that both cytokines participate in the growth inhibition in vivo. Indeed combinations of IFN- $\gamma$ and TNF- $\alpha$ can result in substantial cytolysis of HT29 over a 4-5-d incubation period in vitro (13). Therefore, it is possible that both IFN- $\gamma$ and TNF- $\alpha$ production by the $\mathrm{T}$ cells in vivo plays an important role in therapeutic efficacy of this treatment regimen.

Effect of anti-IFN- $\gamma$ antibodies in vivo on survival in tumor-bearing mice. The in vitro data shown in Tables IV and V implicated rhIFN- $\gamma$ production as a possible mechanism for the antitumor effects of rhIL-7 and AIT in tumor-bearing mice. Therefore, studies were initiated in which neutralizing antibodies to rhIFN- $\gamma$ were administered at the start of rhIL-7 and AIT therapy. The results clearly demonstrate that the anti-IFN- $\gamma$ antibodies significantly inhibited the antitumor effects of rhIL7 and AIT in vivo (Fig. 3). Thus, rhIL-7 promotes rhIFN- $\gamma$ production by human $\mathrm{T}$ cells in vivo in response to the tumor, and, in addition to the improved $T$ cell engraftment stimulated by rhIL-7, the rhIL-7-induced IFN- $\gamma$ can result in significant protection of SCID mice from a human tumor in vivo.

Comparison of systemic rhIFN- $\gamma$ administration and adoptive immunotherapy on survival in tumor-bearing mice. To compare the efficacy of rhIL-7 and AIT versus systemic rhIFN$\gamma$ administration in vivo, tumor-bearing mice received either 2 $\times 10^{5} \mathrm{U}$ i.p. of rhIFN- $\gamma$ daily for $10 \mathrm{~d}$ or rhIL-7 and AIT. The high dose regimen of rhIFN- $\gamma$ was tolerated by the SCID mice because of the species-specificity of rhIFN- $\gamma(15)$ resulting in the lack of toxic side effects that would normally be present if this dosage was applied in man. The results clearly show that even when high doses of rhIFN- $\gamma$ are administered in vivo, little or no protective effects are detected (Fig. 4). In marked contrast, mice given rhIL-7 and AIT demonstrated significant protection against the tumor. The results indicate that AIT is superior to systemic administration of cytokines, possibly because of the sustained local release of cytokines by the human $\mathrm{T}$ cells in vivo.

\section{Discussion}

The data presented here demonstrate that rhIL-7 in combination with AIT consisting of human T cells will protect SCID mice from a human colon carcinoma. The mechanism of the 
protection is dependent on the production of IFN- $\gamma$ by the human $T$ cells. This is the first instance in which rhIL-7 has been demonstrated to exert antitumor effects against a human tumor in vivo and suggests that rhIL-7 should be examined clinically as an antineoplastic agent. The data also demonstrate that although the production of IFN- $\gamma$ is essential for the antitumor effects of rhIL-7 and AIT, systemic administration of this cytokine, while capable of exerting significant antitumor effects in vitro, does not offer comparable protective effects in vivo. This implies that AIT offers distinct advantages as an antitumor therapy, possibly because of sustained and local release of IFN- $\gamma$, and possibly other cytokines from the adoptively transferred cells.

The human/mouse model, while offering many advantages for the preclinical evaluation of potential antineoplastic therapeutics, does have several significant limitations. It is still not clear if primary immune responses with human cells can be generated in SCID mice, although secondary responses have been shown $(11,16)$. Because of the selective pressures accompanying the placement of human $T$ cells in a xenogeneic environment, the antitumor effects of rhIL-7 and AIT may be an indirect effect in response to exposure to the xenoantigens and not the tumor. Experiments are underway to determine if the human $\mathrm{T}$ cells do become specifically sensitized to the tumor in vivo. However, the human/mouse model does allow for the evaluation of anticancer therapies using human reagents directed against human tumors in an in vivo setting. Due to the fact that IFN- $\gamma$ could inhibit tumor growth in vitro and yet systemic administration yielded little protective effect in vivo, this model may be very useful for the evaluation of various other cytokine therapies that have been proposed, since the complex in vivo milieu cannot be reproduced in vitro. Additionally, the model suggests that AIT may be of considerable use, when given in conjunction with rhIL-7 as an antineoplastic regimen. Studies are currently underway comparing the efficacy and toxicities of rhIL-7 and rhIL-2 in this model. It will also be important to test rhIL-7 and AIT against other tumors that are not sensitive to cytokines and to use tumors that are HLA-compatible with the human $\mathrm{T}$ cell donor to evaluate the ability of particular therapies to induce MHC-restricted killing.

It is also of interest that rhIL-7 induced significant cytokine $($ IFN- $\gamma)$ production and not substantial cytolytic ability in the $\mathrm{T}$ cells cultured with the allogeneic tumor. Cytokine production by tumor infiltrating lymphocytes has recently been demonstrated to be a more relevant indicator of antitumor effects in vivo than cytotoxicity (17). Our results also support that expression of in vitro cytotoxicity may not be a critical factor for a successful in vivo response.

In conclusion, rhIL-7 is shown to exhibit antitumor effects when given with AIT against a human tumor in vivo, suggesting that this cytokine may be of benefit as an immunomodulator in vivo and deserves further clinical evaluation. Furthermore, this work illustrates the advantages of performing in vivo evaluation of potential anticancer therapies using the human/ mouse model.

\section{Acknowledgments}

The authors thank Christie Lee Harrison, Kelli Taylor, Louise Finch, Kirk Volker, Tammy Rowe, Eilene Gruys, and Theresa Wiltrout for expert technical assistance. We are also grateful to Terry Phillips for her superb editorial services. We thank Dr. Satoshi Funakoshi for critically reviewing the manuscript.

The content of this publication does not necessarily reflect the views or policies of the Department of Health and Human Services, nor does mention of trade names, commercial products, or organizations imply endorsement by the U. S. Government. Animal care was provided in accordance with the procedures outlined in the "Guide for the Care and Use of Laboratory Animals" (National Institutes of Health Publication No. 86-23, 1985).

\section{References}

1. Goodwin, R. G., S. Lupton, A. Schmierer, K. J. Hjerrild, R. Jerzy, W. Clevenger, S. Gillis, D. Cosman, and A. E. Namen. 1989. Human interleukin 7: molecular cloning and growth factor activity on human and murine B-lineage cells. Proc. Natl. Acad. Sci. USA. 86:302-306.

2. Namen, A. E., S. Lupton, K. Hjerrild, J. Wignall, D. Y. Mochizuki, A. Schmierer, B. Mosley, C. J. March, D. Urdal, S. Gillis, et al. 1988. Stimulation of B-cell progenitors by cloned murine interleukin-7. Nature (Lond.). 333:571-573.

3. Conlon, P. J., P. J. Morrissey, R. P. Nordan, K. H. Grabstein, K. S. Prickett, S. G. Reed, R. Goodwin, D. Cosman, and A. E. Namen. 1989. Murine thymocytes proliferate in direct response to interleukin-7. Blood. 74:1368-1373.

4. Morrissey, P. J., R. G. Goodwin, R. P. Nordan, D. Anderson, K. H. Grabstein, D. Cosman, J. Sims, S. Lupton, B. Acres, S. G. Reed, et al. 1989. Recombinant interleukin 7, pre-B cell growth factor, has costimulatory activity on purified mature T cells. J. Exp. Med. 169:707-716.

5. Welch, P. A., A. E. Namen, R. G. Goodwin, R. Armitage, and M. D. Cooper. 1989. Human IL-7: a novel T cell growth factor. J. Immunol. 143:35623567.

6. Alderson, M. R., H. M. Sassenfeld, and M. B. Widmer. 1990. Interleukin 7 enhances cytolytic $\mathrm{T}$ lymphocyte generation and induces lymphokine-activated killer cells from human peripheral blood. J. Exp. Med. 172:577-587.

7. McBride, W. H., J. D. Thacker, S. Comora, J. S. Economou, D. Kelley, D. Hogge, S. M. Dubinett, and G. J. Dougherty. 1992. Genetic modification of a murine fibrosarcoma to produce interleukin 7 stimulates host cell infiltration and tumor immunity. Cancer Res. 52:3931-3937.

8. Hock, H., M. Dorsch, T. Diamantstein, and T. Blankenstein. 1991. Interleukin 7 induces $\mathrm{CD}^{+} \mathrm{T}$ cell-dependent tumor rejection. J. Exp. Med. 174:1291-1298.

9. Lynch, D. H., A. E. Namen, and R. E. Miller. 1991. In vivo evaluation of the effects of interleukin 2, 4, and 7 on enhancing the immunotherapeutic efficacy of anti-tumor cytotoxic T lymphocytes. Eur. J. Immunol. 21:2977-2985.

10. Jicha, D. L., J. J. Mule, and S. A. Rosenberg. 1991. Interleukin 7 generates antitumor cytotoxic $\mathrm{T}$ lymphocytes against murine sarcomas with efficacy in cellular adoptive immunotherapy. J. Exp. Med. 174:1511-1515.

11. Mosier, D. E., R. J. Gulizia, S. M. Baird, and D. B. Wilson. 1988. Transfer of a functional human immune system to mice with severe combined immunodeficiency. Nature (Lond.). 335:256-259.

12. Rabinowich, H., D. Vitolo, S. Altarac, R. B. Herberman, and T. L. Whiteside. 1992. Role of cytokines in the adoptive immunotherapy of an experimental model of human head and neck cancer by human IL-2-activated natural killer cells. J. Immunol. 149:340-349.

13. Murphy, W. J., K. C. Conlon, T. J. Sayers, R. H. Wiltrout, T. C. Back, J. R. Ortaldo, and D. L. Longo. 1993. Engraftment and activity of anti-CD3-activated human peripheral blood lymphocytes transferred into mice with severe combined immune deficiency. J. Immunol. 150:3634-3642.

14. Murphy, W. J., M. Bennett, M. R. Anver, M. Baseler, and D. L. Longo. 1992. Human-mouse lymphoid chimeras: host-vs.-graft and graft-vs.-host reactions. Eur. J. Immunol. 22:1421-1427.

15. Grabstein, K. H., A. E. Namen, K. Shanebeck, R. F. Voice, S. G. Reed, and M. B. Widmer. 1990. Regulation of T cell proliferation by IL-7. J. Immunol. 144:3015-3020.

16. McCune, J. M., R. Namikawa, H. Kaneshima, L. D. Shultz, M. Lieberman, and I. L. Weissman. 1988. The SCID-hu mouse: murine model for the analysis of human hematolymphoid differentiation and function. Science (Wash. DC) 241:1632-1639.

17. Barth, R. J., Jr., J. J. Mule, P. J. Spiess, and S. A. Rosenberg. 1991. Interferon $\gamma$ and tumor necrosis factor have a role in tumor regressions mediated by murine $\mathrm{CD}^{+}$tumor infiltrating lymphocytes. J. Exp. Med. 173:647-658. 